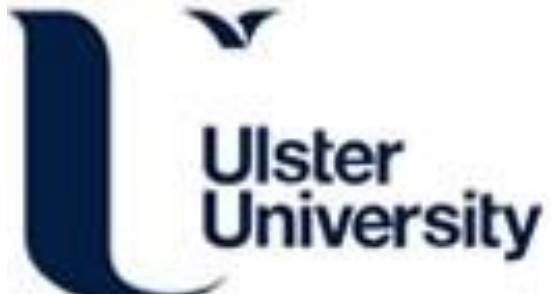

\section{A new stable GIP-Oxyntomodulin hybrid peptide improved bone strength both at the organ and tissue levels in genetically-inherited type 2 diabetes mellitus}

Mansur, SA., Mieczkowska, A., Flatt, P., Bouvard, B., Chappard, D., Irwin, N., \& Mabilleau, G. (2016). A new stable GIP-Oxyntomodulin hybrid peptide improved bone strength both at the organ and tissue levels in genetically-inherited type 2 diabetes mellitus. Bone, 87, 102-113. https://doi.org/10.1016/j.bone.2016.04.001

Link to publication record in Ulster University Research Portal

Published in:

Bone

Publication Status:

Published online: 08/04/2016

DOI:

10.1016/j.bone.2016.04.001

Document Version

Author Accepted version

\section{General rights}

Copyright for the publications made accessible via Ulster University's Research Portal is retained by the author(s) and / or other copyright owners and it is a condition of accessing these publications that users recognise and abide by the legal requirements associated with these rights.

\section{Take down policy}

The Research Portal is Ulster University's institutional repository that provides access to Ulster's research outputs. Every effort has been made to ensure that content in the Research Portal does not infringe any person's rights, or applicable UK laws. If you discover content in the Research Portal that you believe breaches copyright or violates any law, please contact pure-support@ulster.ac.uk. 


\section{Accepted Manuscript}

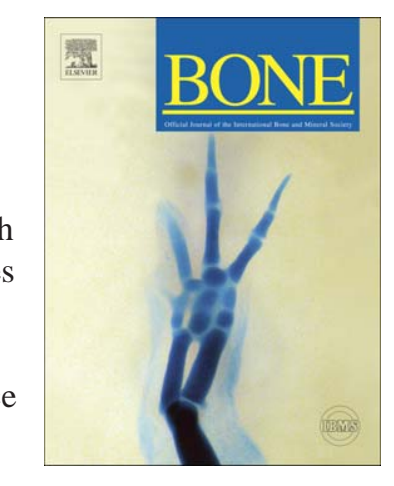

A new stable GIP-Oxyntomodulin hybrid peptide improved bone strength both at the organ and tissue levels in genetically-inherited type 2 diabetes mellitus

Sity Aishah Mansur, Aleksandra Mieczkowska, Peter R. Flatt, Beatrice Bouvard, Daniel Chappard, Nigel Irwin, Guillaume Mabilleau

PII: $\quad$ S8756-3282(16)30088-6

DOI: $\quad$ doi: $10.1016 /$ j.bone.2016.04.001

Reference: $\quad$ BON 11005

To appear in: Bone

Received date: 6 October 2015

Revised date: $\quad 30$ March 2016

Accepted date: $\quad 4$ April 2016

Please cite this article as: Mansur Sity Aishah, Mieczkowska Aleksandra, Flatt Peter R., Bouvard Beatrice, Chappard Daniel, Irwin Nigel, Mabilleau Guillaume, A new stable GIP-Oxyntomodulin hybrid peptide improved bone strength both at the organ and tissue levels in genetically-inherited type 2 diabetes mellitus, Bone (2016), doi: 10.1016/j.bone.2016.04.001

This is a PDF file of an unedited manuscript that has been accepted for publication. As a service to our customers we are providing this early version of the manuscript. The manuscript will undergo copyediting, typesetting, and review of the resulting proof before it is published in its final form. Please note that during the production process errors may be discovered which could affect the content, and all legal disclaimers that apply to the journal pertain. 
A new stable GIP-Oxyntomodulin hybrid peptide improved bone strength both at the organ and tissue levels in genetically-inherited type 2 diabetes mellitus

Sity Aishah Mansur ${ }^{1,2}$, Aleksandra Mieczkowska ${ }^{3}$, Peter R Flatt ${ }^{1}$, Beatrice Bouvard ${ }^{3}$, Daniel Chappard $^{3,4}$, Nigel Irwin ${ }^{1}$, Guillaume Mabilleau ${ }^{3,4}$

1 University Tun Hussein Onn Malaysia, Johor, Malaysia

2 School of Biomedical Sciences, University of Ulster, Coleraine, Northern Ireland, United Kingdom

3 GEROM Groupe Etudes Remodelage Osseux et bioMatériaux - LHEA, IRIS-IBS Institut de Biologie en Santé, CHU d'Angers, LUNAM Université, 49933 ANGERS Cedex FRANCE.

4 SCIAM, Service Commun d'Imagerie et Analyses Microscopiques, IRIS-IBS Institut de Biologie en Santé, CHU d'Angers, LUNAM Université, 49933 ANGERS Cedex FRANCE.

Please send all correspondence to:

Guillaume Mabilleau, PhD

GEROM-LHEA UPRES EA 4658

Institut de Biologie en Santé

Université d'Angers

4 rue larrey

49933 Angers Cedex 09

France
푱 : $+33(0) 244688349$

Fax : +33(0) 244688451

$\bowtie:$ guillaume.mabilleau@univ-angers.fr

Abstract word count: 216 words

Manuscript word count: 5,544 words 


\section{ABSTRACT}

Obesity and type 2 diabetes mellitus (T2DM) progress worldwide with detrimental effects on several physiological systems including bone tissue mainly by affecting bone quality. Several gut hormones analogues have been proven potent in ameliorating bone quality. In the present study, we used the leptin receptor-deficient $d b / d b$ mice as a model of obesity and severe T2DM to assess the extent of bone quality alterations at the organ and tissue levels. We also examined the beneficial effects of gut hormone therapy in this model by using a new triple agonist ([D-Ala $\left.{ }^{2}\right]$ GIP-Oxm) active at the GIP, GLP-1 and glucagon receptors. As expected, $d b / d b$ mice presented with dramatic alterations of bone strength at the organ level associated with deterioration of trabecular and cortical microarchitectures and an augmentation in osteoclast numbers. At the tissue level, these animals presented also with alterations of bone strength (reduced hardness, indentation modulus and dissipated energy) with modifications of tissue mineral distribution, collagen glycation and collagen maturity. The use of [DAla $^{2}$ GIP-Oxm considerably improved bone strength at the organ level with modest effects on trabecular microarchitecture. At the tissue level, [D-Ala²]GIP-Oxm ameliorated bone strength reductions with positive effects on collagen glycation and collagen maturity. This study provides support for including gut hormone analogues as possible new therapeutic strategies for improving bone quality in bone complications associated to T2DM.

Keywords: Type 2 diabetes mellitus, [D-Ala²]GIP-Oxm, bone quality, bone strength, $d b / d b$ mice 


\section{INTRODUCTION}

Obesity is a major predisposing factor for the development of type 2 diabetes mellitus (T2DM). It accounts for $80-85 \%$ of the overall risk of developing T2DM and underlies the marked worldwide increase in the incidence of this condition [1]. In the last decade, several studies reported that obesity and T2DM make an important impact on the skeleton. Despite inconsistencies in the reporting of the effects of body mass on bone metabolism, bone impairments are clearly evident in established rodent models of obesity and insulin resistance [2-5]. Several bone-related hormones are altered in these animal models of obesity including leptin, which serves as an important regulator of body weight $[6,7]$. The long form of the leptin receptor is encoded by the $d b$ gene and a recessive mutation in this gene has been shown to affect the intracellular domain of the single membrane-spanning receptor [8]. Although leptin appears to bind to its receptor in mutant homozygous $d b / d b$ mice [9], defective intracellular signal transduction attenuates leptin function, leading to a characteristic phenotype of severe obesity and diabetes $[10,11]$. As such, leptin receptor-deficient $(d b / d b)$ mice represent a genetic rodent model of spontaneous obesity as well as genetically-inherited T2DM. Indeed, db/db mice exhibit early onset obesity with hyperinsulinemia, hyperlipidaemia, insulin resistance and pancreatic $\beta$-cell dysfunction culminating in severe age-related hyperglycemia $[10,11]$. These animals also exhibit macrovascular complications and nephropathy, complications often found in human T2DM patients [12]. Several investigators have studied the impact of leptin on bone physiology reporting a dual action of central and peripheral leptin on bone mass and strength using either $o b / o b$ mice, $d b / d b$ mice or leptin receptor-deficient fa/fa rats [5, 13-17]. However, an important aspect of these animals is the obesity-diabetes that could possibly play a role in the reduction of bone strength, in addition to the direct actions of leptin signalling pathways in bone.

In response to nutrient intake, two incretin hormones, namely glucose-dependent insulinotropic polypeptide (GIP) and glucagon-like peptide-1 (GLP-1) are released by enteroendocrine cells in the gastrointestinal tract. The primary physiological target of these gut hormones is the pancreatic $\beta$ cell, where these hormones stimulate insulin secretion and thereby contribute to the control blood glucose concentrations [18]. As such, the action of incretin hormones have therapeutic potential for the treatment of type 2 diabetes, as indicated by the current clinical use of GLP-1 mimetics [19]. Recently, a growing body of evidence suggests that incretins could also be beneficial for bone strength. Indeed, the importance of GIP and GLP-1 signalling in normal bone regulation was revealed in genetically-modified knockout and transgenic mice where the ablation of GIP or GLP-1 receptors led to dramatic alterations of trabecular and cortical microarchitecture as well as detrimental effects on tissue material properties of bone [20-26]. Furthermore, administration of GIP or GLP-1 agonists to healthy or type 1 diabetic rodent models significantly improved tissue material properties within a month $[23,27]$. Recently, it has also been demonstrated that polymorphism at the GIP receptor locus was associated with lower bone mineral density and greater incidence of non-vertebral fractures [28]. Taken together, these data suggest beneficial effects of GIP and GLP-1 signalling on bone. Nonetheless, endogenous incretins are a substrate of dipeptidyl peptidase-4 (DPP-4) and the gut hormones are rapidly cleaved by this serine protease enzyme, yielding the inactive truncated 
forms of these peptides. In order to circumvent DPP-4 activity, several stable long-acting incretin analogues have been developed and evaluated for their glucose-lowering and insulin-releasing properties [29].

Intestinal enteroendocrine cells produce several other hormones, including oxyntomodulin $(\mathrm{Oxm})$, which is a 37-amino acid peptide, derived from the proglucagon gene and co-secreted with GLP-1 following feeding. Oxm exerts its effects by binding to and co-activating both glucagon and GLP-1 receptors to stimulate insulin secretion and reduce blood glucose [30, 31]. Oxm is also involved in the regulation of energy expenditure and food intake, leading to reduction of body weight [32]. Much recent research suggests that stable analogues of Oxm might be useful for the treatment of obesitydiabetes [29]. In addition, several N-terminally modified stable GIP peptides, such as (D-Ala ${ }^{2}$ )GIP [33], have significant antidiabetic activity. Based on these observations, [D-Ala ${ }^{2}$ ]GIP-Oxyntomodulin has been generated by our group in order to activate GIP, GLP-1 and glucagon receptors. The efficacy of [D-Ala ${ }^{2}$-GIP-Oxm as a triple agonist and to reduce hyperglycaemia has been established in high fatfed mice, which exhibit a mild form of diabetes [34]. Taking into consideration the capacity of this peptide to activate GIP and GLP-1 receptor pathways, important for bone strength, [D-Ala ${ }^{2}$ GIPOxyntomodulin is viewed as potential therapeutic agent in management of bone alterations in diabetes.

The aims of the present study were (i) to conduct a thorough investigation of microarchitectural and material properties of bone in leptin receptor deficient mice, that represent a severe form of T2DM, and (ii) to assess whether the multiple agonist peptide [D-Ala ${ }^{2}$ GIP-Oxm could represent a useful means of improving bone quality and strength in this condition [35].

\section{MATERIAL AND METHODS}

\section{[D-Ala $]$ GIP-Oxm}

[D-Ala²]GIP-Oxm was purchased from GL Biochem Ltd. (Shanghai, China), and identified by matrixassisted laser desorption/ionization-time of flight mass spectrometry (MALDI-TOF MS). Briefly, $1.5 \mu \mathrm{l}$ of peptide $(1 \mathrm{mg} / \mathrm{ml})$ solution was dispensed onto a well of a 100-well stainless steel MALDI plate and allowed to dry at room temperature. Matrix solution $(1.5 \mu \mathrm{l} ; 10 \mathrm{mg} / \mathrm{ml}$ of $\alpha$-cyano-4-hydroxycinnamic acid in acetonitrile; Sigma-Aldrich, Poole, UK) was added to the dried peptides and the mixture was again left to dry. The molecular mass of peptide was determined using a Voyager-DE BioSpectrometry Workstation (PerSeptive BioSystems, Framingham, MA, USA) and recorded as mass-to-charge $(\mathrm{m} / \mathrm{z})$ ratio vs percentage intensity of peak. The observed molecular mass for [D-Ala²]GIP-Oxm was 4472.3 Da corresponding to theoretical value of $4473.0 \mathrm{Da}$. Characteristics of [D-Ala²]GIP-Oxm are presented in Table 1.

\section{Animals}

Eleven-week-old male db/db mice (mouse strain BKS.Cg- + Lepr $/+L e p r^{d b} / O l a H s d$ ) were obtained from Harlan Ltd (Harlan LTD., Blackthorn, UK). These animals carry an autosomal recessive mutation on 
chromosome 4 that results in leptin receptor deficiency. Age- and sex-matched lean wild type animals $\left(\mathrm{n}=10\right.$; mouse strain BKS.Cg-Dock $7^{m}+1+L e p r^{\text {bb }} / \mathrm{OlaHsd}$ ) from Harlan with the same genetic background were used as controls. Male $d b / d b$ mice were randomly allocated into two groups ( $\mathrm{n}=10 /$ group) that received [D-Ala ${ }^{2}$-GIP-Oxm (50 nmol/kg bw) or saline vehicle $(0.9 \%, \mathrm{w} / \mathrm{v}, \mathrm{NaCl})$ once daily for 21 days. This dose was chosen on the basis of positive results obtained with [D-Ala²]GIPOxm in on our previous studies in high fat fed mice [34]. In order to dissociate possible direct effects on bone from actions arising from improved glycaemic control we decided to use the same dose (50 $\mathrm{nmol} / \mathrm{kg} \mathrm{bw}$ ) even though $\mathrm{db} / \mathrm{db}$ mouse present with a much more severe form of diabetes associated with insulin resistance, beta-cell dysfunction and islet degeneration [36]. Lean mice were treated with saline vehicle for the same period of time.

Mice were caged individually in an air-conditioned room at $22 \pm 2^{\circ} \mathrm{C}$ with $12 \mathrm{~h}$ light: $12 \mathrm{~h}$ dark cycle with free access to standard rodent diet (10\% fat, 30\% protein, $60 \%$ carbohydrate; Trouw Nutrition, Cheshire, UK). Body weight, food consumption, non-fasting blood glucose and plasma insulin concentrations were monitored regularly during the 21-day experimental period in diabetic mice. An overnight fasted glucose tolerance (18 mmol/kg bw; ip) test was carried out at the end of the study as described previously [34]. Plasma glucose was determined by the glucose oxidase method using Analox analyser GM-9 with Analox instruments glucose reagent. Plasma insulin was determined by a modified dextran-coated charcoal radioimmunoassay (RIA) [37].The mice were also administered calcein (10 mg/kg bw; ip) 9 and 2 days before being culled by inhalation of $\mathrm{CO}_{2}$, to estimate the levels of newly formed bone. After necropsy, tibias and femurs were collected and cleaned of soft tissue. Tibias were fixed with a formalin-based fixative whilst femurs were stored in $70 \%$ ethanol. All experiments were approved by the local animal care and welfare committee and conducted according to the principles of laboratory animal care (NIH publication no.85-23, revised 1985), the United Kingdom Office regulations (UK Animals Scientific Procedures Act 1986 revised in January 2013) and the European Union directive 2010/63/EU.

\section{Dual-Energy X-ray absorptiometry (DEXA)}

Bone mineral density $\left(B M D, g / \mathrm{cm}^{2}\right)$, bone mineral content (BMC, g) and total body fat $(\mathrm{g})$ were measured with a Lunar PIXImus DEXA scanner (Inside Outside Sales, Wisconsin, U.S.A.). Mice were anaesthetised with isoflurane and pentobarbital sodium (10 $\mu \mathrm{l} / \mathrm{g} \mathrm{bw})$ and then placed on a specimen tray. The animals were exposed to low energy $X$-rays and a high-resolution picture $(0.18 \times 0.18 \mathrm{~mm}$ pixel size) was captured of the x-rays hitting a luminescent panel. The whole body was scanned and regions of interests (ROIs) were manually drawn over the spine, tibias or whole body. Quality control was performed on daily intervals before acquiring data and calibration of the DEXA machine was performed using the phantom provided by the manufacturer.

\section{Microcomputed tomography (microCT)}

MicroCT analysis was performed on tibias with a Skyscan 1172 microtomograph (Bruker MicroCT, Kontich, Belgium) operated at $70 \mathrm{kV}, 100 \mu \mathrm{A}, 340$-ms integration time. The isotropic pixel size was fixed at $3.75 \mu \mathrm{m}$, the rotation step at $0.25^{\circ}$ and exposure was done with a $0.5-\mathrm{mm}$ aluminium filter. 
Each 3D reconstruction image dataset was binarized using global thresholding. Trabecular parameters were assessed in the proximal secondary spongiosa $0.5 \mathrm{~mm}$ below the growth plate and extending $2 \mathrm{~mm}$ down. Bone volume (BV/TV, in \%), trabecular number (Tb.N, $/ \mathrm{mm}$ ), trabecular thickness (Tb.Th, in $\mu \mathrm{m}$ ) and trabecular separation (Tb.Sp, in $\mu \mathrm{m}$ ) were determined with the CTan software (Bruker MicroCT). Cortical parameters were assessed at the midshaft tibia. Cortical VOls extended on 1-mm centred at the midshaft tibia. Total cross-sectional area (Tt.Ar, in $\mathrm{mm}^{2}$ ), medullary area (Ma.Ar, in $\mathrm{mm}^{2}$ ), cortical bone area (Ct.Ar, in $\mathrm{mm}^{2}$ ), cortical area fraction (Ct.Ar/Tt.Ar, in \%), average cortical thickness (Ct.Th, in $\mu \mathrm{m}$ ) and cortical porosity (Ct.Po, in \%) were measured with a lab-based routine running in Matlab 8.4 (Mathworks, Natick, MA). All these parameters were determined according to guidelines and nomenclature proposed by the American Society for Bone and Mineral Research [38].

\section{Bone histomorphometry}

After microCT scans, tibias were cut at the mid-diaphysis and embedded, undecalcified in poly (methylmethacrylate) (pMMA) at $4^{\circ} \mathrm{C}$ to preserve enzyme activities [39]. In order to assess trabecular tissue, longitudinal sections of the proximal tibia segment were performed. On the other hand, for cortical assessment, we cut perpendicularly to the long bone axis the upper part of the distal segment. For each animal, four non serial sections ( $\sim 50 \mu \mathrm{m}$ apart) were left unstained for the measurement of calcein-based parameters and four additional sections were stained for the osteoclastic tartrate resistant acid phosphatase (TRAcP) as previously described [40]. Only TRAcP-positive nucleated cells in contact with bone were counted as osteoclasts. The trabecular region of interest (ROI) was located in the secondary spongiosa $0.5 \mathrm{~mm}$ below the growth plate on a height of $2 \mathrm{~mm}$. Standard bone histomorphometrical nomenclatures, symbol and units were used as described in the guidelines of the American Society for Bone and Mineral Research [41]. The identity of the section was not revealed until the end of all measurements.

\section{Circularized light microscopy}

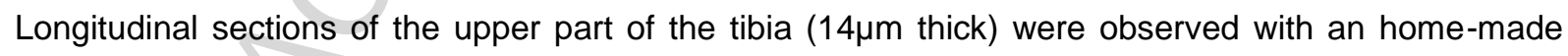
circularly polarized light mounted on an Olympus AX-60 microscope (Olympus France, Rungis, France). Regions of interest were positioned on cortical bone. Briefly, two circular polarizers were inserted in the light path, one below the specimen and the second one above the specimen. These two circularizers were equipped with crossed Nicol's prism and a $\lambda / 4$ compensator to eliminate the Maltese cross effect. Circularly polarized lights detect the anisotropy of bone through "bright" and "extinct" signals owing to birefringence of collagen [42]. For quantitation of birefringence signal, illumination intensity and the threshold for distinguishing bright and extinct signal were kept constant for all specimens; then percent area occupied by bright birefringent signals at the proximal and middle tibia was quantitated with ImageJ.

\section{Three-point bending}

Three-point bending experiments were performed on femurs to assess bone strength at the organ level. Prior to mechanical testing, femurs were rehydrated in saline overnight at $4^{\circ} \mathrm{C}$. Measurements 
were done with a constant span length of $10 \mathrm{~mm}$ on an Instron 5942 (Instron, Elancourt, France). The press head as well as the two support points were rounded to avoid shear load and cutting. Femurs were positioned horizontally with the anterior surface facing downward, centred on the support and the pressing force was applied vertically to the midshaft of the bone. A pre-load of $1 \mathrm{~N}$ was applied to ensure correct positioning of the femur. Each bone was tested with a loading speed of $2 \mathrm{~mm} \cdot \mathrm{min}^{-1}$ until failure with a $500 \mathrm{~N}$ load cell as previously published [43]. The load-displacement curve was acquired with the Bluehill 3 software (Instron). Ultimate load, ultimate displacement, stiffness and total absorbed energy were computerized according to previously published equations [44].

\section{Fourier-transform infrared microscopy (FTIRM)}

After three-point bending experiments, femurs were cross-sectionally cut at the midshaft using a diamond saw (Accutom, Struers, Champigny sur Marne, France) and embedded undecalcified in polymethylmethacrylate at $4^{\circ} \mathrm{C}$ as previously reported [39]. Cross-sections (4um thickness) of the midshaft femur were sandwiched between $\mathrm{BaF}_{2}$ optical windows. Spectral analysis were obtained on a Bruker Vertex 70 spectrometer (Bruker optics, Ettlingen, Germany) interfaced with a Bruker Hyperion 3000 infrared microscope as previously reported [20]. For FTIR analysis at site of bone formation, 12 spectra on each bone were acquired between double calcein labelling and analysed with the Opus Software (release 6.5, Bruker). The contribution of the embedding polymethylmethacrylate (pMMA) and water vapour were corrected for each spectrum prior to baseline correction. Individual spectra were then subjected to curve fitting after second derivative using a commercially available software package (Grams/Al 8.0, Thermofisher scientific, Villebon sur Yvette, France) as previously reported [45]. The evaluated IR spectral parameters were (1) mineral-to-matrix ratio which reflects the degree of mineralization of the bone matrix, calculated from the ratio of integrated areas of the phosphate $v 1$, u3 band at $900-1200 \mathrm{~cm}^{-1}$ to the amide I band at $1585-1725 \mathrm{~cm}^{-1}$ [46]; (2) mineral maturity, which reflects the apatite size and perfection, calculated as the ratio of the relative intensity of subbands at 1020 and $1030 \mathrm{~cm}^{-1}$ of the phosphate band [47]; (3) the carbonate to phosphate ratio, which reflects the carbonate content in bone and determined by the ratio of integrated areas of the $\mathrm{v} 2 \mathrm{CO}_{3}{ }^{2-}$ region $(850-890 \mathrm{~cm}-1)$ to the $v 1, v 3$ phosphate band $\left(900-1200 \mathrm{~cm}^{-1}\right)$ [47]; and (4) the collagen maturity index, determined as the relative ratio of subbands located at $1660 \mathrm{~cm}^{-1}$ and $1690 \mathrm{~cm}^{-1}$ of the amide I peak, was assessed [48]. Then, bone sections were demineralized with EDTA and reanalysed by FTIRM at the same location as described in detail elsewhere [45]. The collagen glycation index was investigated as the area ratio of the $1032 \mathrm{~cm}^{-1}$ subpeak over the amide I region. The collagen integrity index was determined as the area ratio of the $1338 \mathrm{~cm}^{-1}$ band over the amide II region.

\section{Nanoindentation}

Nanoindentation tests evaluated the mechanical properties at the tissue level. PMMA blocks used for FTIRM sections were polished to a 1- $\mu \mathrm{m}$ finish with diamond particles (Struers, France). Prior to nanoindentation testing, blocks were rehydrated for $24 \mathrm{hrs}$ in saline at $4^{\circ} \mathrm{C}$. Prior to testing, the probe area function and instrument frame compliance were calibrated using a fused silica sample. Twelve indentations, at distance from canals, osteocyte lacunae and/or microcracks were randomly positioned 
in cortical bone with a NHT-TTX system (CSM, Peseux, Switzerland) equipped with a Berkowitch diamond probe as the indenter and an optical system to control where indentation are positioned. Indentations were made up to a depth of $900 \mathrm{~nm}$ with a loading/unloading rate of $40 \mathrm{mN} / \mathrm{min}$. At maximum load, a holding period of 15 seconds was applied to avoid creeping of the bone material. The following material properties at the tissue-level, maximum load, indentation modulus, hardness and dissipated energy, were determined according to Oliver and Pharr [49].

\section{Bone mineral density distribution (BMDD) evaluation}

Quantitative backscattered electron imaging (qBEI) was employed to determine BMDD as previously reported [27]. QBEI experiments were performed on the same blocks as nanoindentation and FTIRM. Polymethylmethacrylate blocks were carbon-coated and observed with a scanning electron microscope (EVO LS10, Carl Zeiss Ltd, Nanterre, France) equipped with a five quadrant semiconductor backscattered electron detector. The microscope was operated at $20 \mathrm{keV}$ with a probe current of $250 \mathrm{pA}$ and a working distance of $15 \mathrm{~mm}$. The backscattered signal was calibrated using pure carbon $(Z=6$, mean grey level $=25)$, pure aluminium $(Z=13$, mean grey level $=225)$ and pure silicon $(Z=14$, mean grey level $=253$ ) standards (Micro-analysis Consultants Ltd, St Ives, UK). The cortical bone area was imaged at a $200 \mathrm{X}$ nominal magnification, corresponding to a pixel size of 0.5 $\mu \mathrm{m} /$ pixel. Four images per samples were taken. Two variables were obtained from the bone mineral density distribution: $\mathrm{Ca}_{\text {mean }}$ as the average calcium concentration and $\mathrm{Ca}_{\text {width }}$ as the width of the histogram at half maximum of the peak. Following this, the blocks were imaged at an X200 magnification with a confocal microscope (Leica SP8, Leica, Nanterre, France) equipped with an argon laser at $488 \mathrm{~nm}$ and a hybrid GaAs detector (Leica) to find bone surface with double labels. Confocal images were superimposed on qBEl images in order to delineate new bone matrix formed during the time-course of the study. Using ImageJ $1.49 \mathrm{v}$, a straight line (4 pixel width) perpendicular to the mineralization front across the new bone structural unit with a step size of $0.5 \mu \mathrm{m}$ was drawn on qBEl image. The calcium content was plotted vs. distance of mineralization front. These plots show a biphasic aspect with fast mineralization process close to the mineralization front followed by a slow mineralization process. The two mineralization processes were then analysed by linear curve-fitting with a lab-made routine in Excel 2010 (Microsoft, Issy-les-Moulineaux, France). $\mathrm{Ca}_{\text {turn }}$ was determined as the calcium concentration where the fast mineralization process was changing to the slow mineralization process as described by Roschger et al., [50].

\section{Statistical analysis}

Results were expressed as mean \pm standard error of the mean (SEM). Analysis of variance (ANOVA) was used to compare overall difference among the three groups, followed by t-test when significant differences were detected using GraphPad Prism 5.0 (GraphPad Software Inc, La Jolla, CA). Differences at $p<0.05$ were considered to be significant. 


\section{RESULTS}

\section{[D-Ala'] GIP-Oxm exerts modest effects on metabolic parameters}

Saline treated $\mathrm{db} / \mathrm{db}$ mice exhibited a severe form of diabetes with plasma glucose concentrations > $30 \mathrm{mmol} / \mathrm{l}$ (Table 2). Treatment with [D-Ala ${ }^{2}$ GIP-Oxm for 21 days had no significant effect on body weight or food intake in diabetic mice (Table 2). Non-fasting glucose concentrations in [D-Ala ${ }^{2}$ GIPOxm-treated diabetic mice were reduced from day 10 onwards, however the values did not reach statistical significance (Supplementary Figure 1). On the other hand, plasma insulin levels were significantly increased on day 21 (3-fold, $\mathrm{p}<0.01$ ) in mice treated with [D-Ala ${ }^{2}$ ]GIP-Oxm compared to diabetic saline controls. As shown in Table 2, once daily administration of [D-Ala ${ }^{2}$ GIP-Oxm had no significant effect on glucose tolerance or insulin response to glucose loading (Table 2).

\section{[D-Ala'] GIP-Oxm had no effect on body composition and bone mass assessed by DEXA}

Diabetic mice had significantly higher percentage of body fat compared to lean littermates $(70 \%$ increase, $p<0.01$, Table 2). Treatment with [D-Ala ${ }^{2}$ GIP-Oxm had no significant effect on total fat mass in diabetic mice. There were no differences in BMD and BMC at regions of interest between [D$\mathrm{Ala}^{2}$ ]GIP-Oxm and saline-treated diabetic mice (Table 2). However, diabetic mice exhibited a significant decrease in whole body BMD $(-24 \%, \mathrm{p}<0.001)$ and BMC $(-50-59 \%, \mathrm{p}<0.001)$ as well as at lumbar (BMD: 33 - 38\% decrease, $p<0.001$; BMC: 53 - 63\% decrease, $p<0.001$ ) and tibia (BMD: 21 $26 \%$ decrease, $p<0.001$; BMC: $45 \%$ decrease, $p<0.001$ ) compared to control mice.

\section{[D-Ala $]$ GIP-Oxm exerted a modest effect on bone strength at the organ level in diabetic mice}

We next investigated whether [D-Ala $]$ GIP-Oxm could reverse the reduced bone strength observed in diabetic mice. Figure $1 \mathrm{~A}$ represents examples of load/deformation curves that were recorded in salinetreated controls, saline- and [D-Ala²]GIP-Oxm-treated diabetic mice. All study parameters were significantly decreased in saline-treated diabetic mice as compared with saline-treated control mice (Figure 1B). On the other hand, [D-Ala²]GIP-Oxm-treated diabetic mice exhibited significant augmentations in ultimate displacement $(96 \%, p<0.01)$ and work-to-failure $(90 \%, p<0.01)$ as compared to saline-treated diabetic controls.

\section{[D-Ala ] GIP-Oxm ameliorated trabecular microarchitecture in diabetic mice}

Trabecular bone microarchitecture was investigated at the proximal metaphysis of the tibia. Figure $2 \mathrm{~A}$ shows 3D-models of trabecular bone in saline-treated controls and both saline- and [D-Ala²]GIP-Oxmtreated diabetic mice. These models suggest that trabecular bone mass is reduced in saline-treated diabetic mice as compared with normal control mice. However, [D-Ala²]GIP-Oxm seemed to partially preserve trabecular bone mass. Indeed, all microarchitectural parameters indicated a deterioration of the trabecular bone network in saline-treated diabetic mice as compared with saline-treated controls (Figure 2B). On the other hand, treatment of diabetic mice with [D-Ala²]GIP-Oxm significantly prevented the degradation in BV/TV $(20 \%$ vs. saline-treated diabetic mice, $p<0.05)$, Tb.Th $(11 \%$, $\mathrm{p}<0.05)$, and $\mathrm{Tb} . \mathrm{Sp}(-12 \%, \mathrm{p}<0.05)$. Bone histomorphometry revealed a significant augmentation in N.Oc/B.Pm (300\%, p<0.01) and a non-significant increase in BFR/BS $(44 \%, p=0.22)$ in saline-treated 
diabetic animals as compared with saline-treated controls. In contrast, [D-Ala²]GIP-Oxm-treated diabetic animals presented with significant reductions in N.Oc/B.Pm $(-31 \%, p<0.05)$ and BFR/BS ($46 \%, p<0.05)$ as compared with saline-treated mice. Marrow adiposity was significantly augmented in saline- and GIP-Oxm-treated diabetic mice as compared with saline-treated controls $(p<0.05)$.

\section{[D-Ala $\left.{ }^{2}\right]$ GIP-Oxm did not improve cortical microarchitecture in diabetic mice}

Cortical bone microarchitecture was dramatically altered in diabetic animals as demonstrated in the 3D models in Figure 3A. Indeed, total cross-sectional area, cortical bone area, cortical area fraction, cortical thickness and cortical porosity were significantly lowered in saline-treated diabetic mice as compared with normal saline-treated controls (Figure 3B). However, despite small increases in Ct.Ar, Ct.Ar/Tt.Ar and Ct.Th in [D-Ala²]GIP-Oxm-treated diabetic mice, none of these parameters reached

statistical significance. At the cellular level, Ct.MAR was significantly elevated in saline-treated diabetic animals compared with saline-treated controls (130\%, p<0.001). Similarly, N.Oc/Es.S $(187 \%, p<0.05)$ and N.Oc/Ps.S $(100 \%, p<0.05)$ were elevated in saline-treated diabetic animals compared with salinetreated controls. In contrast, short-term treatment with [D-Ala²]GIP-Oxm significantly reduced Ct.MAR $(-39 \%, p<0.05)$ and N.Oc/Es.S $(-51 \%, p<0.05)$ in diabetic mice as compared to saline-treated animals. N.Oc/Ps.S was also reduced in [D-Ala ${ }^{2}$ GIP-Oxm-treated diabetic mice $(-42 \%, p=0.10)$, although this parameter did not reach statistical significance.

\section{[D-Ala ${ }^{2}$ GIP-Oxm improved bone strength at the tissue level in diabetic mice}

As several mechanical parameters were improved at cortical site without apparent effects of [D$\mathrm{Ala}^{2}$ ]GIP-Oxm on microarchitectural properties, we investigated the mechanical behaviour at the tissue level (Figure 4). Hardness, indentation modulus and dissipated energy were significantly decreased in saline-treated diabetic mice as compared with saline-treated control animals. [D-Ala²]GIP-Oxm resulted in higher values for hardness $(25 \%, p<0.05)$ and indentation modulus $(8 \%, p<0.05)$ as compared with saline-treated diabetic animals. [D-Ala 2 GIP-Oxm had no effects on improving dissipated energy $(\mathrm{p}=0.33)$.

\section{$\left[D-A l a^{2}\right] G I P-O x m$ did not profoundly modify the bone mineral density distribution in diabetic mice}

The tissue mineral density distribution was evaluated by qBEI at cortical site. The calcium content of the entire width of cortical bone was mapped and it appeared that diabetic mice presented with greater calcium content as compared to control animals (Figure $5 \mathrm{~A}$ ). $\mathrm{Ca}_{\text {mean }}$ and $\mathrm{Ca}_{\text {width }}$ were significantly augmented in saline-treated diabetic mice as compared to saline-treated control animals (Figure 5B). [D-Ala2] GIP-Oxm did not modify these profiles. As the treatment period was relatively short, we next examined calcium content in newly-formed bone. The biphasic profile of calcium increase, assessed by the distance from mineralization front, is presented Figure $5 \mathrm{C}$. $\mathrm{Ca}_{\text {turn }}$ values were significantly increased in saline-treated diabetic animals as compared to saline-treated controls $(20 \%, p<0.01)$. On the other hand, [D-Ala2] GIP-Oxm significantly reduced $\mathrm{Ca}_{\text {turn }}$ values $(-10 \%, \mathrm{p}<0.01)$ as compared with saline-treated diabetic controls, to achieve levels similar to those of normal mice. We then ascertained 
whether collagen orientations were modified in $\mathrm{db} / \mathrm{db}$ mice and indeed, saline-treated $\mathrm{db} / \mathrm{db}$ mice exhibited a significant $82 \%$ reduction in this parameter along the long axis of the bone as compared with control animals $(p<0.01$; Figure $5 \mathrm{D})$. On the other hand, GIP-Oxm-treated $\mathrm{db} / \mathrm{db}$ mice exhibited similar collagen orientations as evidenced in control animals.

\section{[D-Ala $]$ GIP-Oxm improved tissue material properties at bone formation site in diabetic mice}

Investigation of tissue material properties at bone formation site was investigated by FTIRM (Figure 6). Although the mineral/matrix ratio followed a similar pattern as observed for $\mathrm{Ca}_{\text {turn }}$, this parameter was not significantly different between the three groups of animals. Mineral maturity and carbonate/phosphate were similar in the three groups of animals. However, saline-treated diabetic mice presented with significant modifications in collagen glycation $(25 \%, p<0.05)$ and collagen maturity $(-18 \%, p<0.01)$ compared with control animals. Treatment with [D-Ala 2$]$ GIP-Oxm significantly reduced collagen glycation $(-13 \%, p<0.05)$ and significantly increased collagen maturity $(17 \%, p<0.05)$ compared with saline-treated diabetic mice.

\section{DISCUSSION}

In this study, an established genetically-inherited model of obesity and diabetes, the diabetic ( $d b / d b)$ mouse, was employed to examine the effects of [D-Ala ${ }^{2}$ GIP-Oxm on bone strength and quality at the organ and tissue levels. These mice presented with significant reductions in cortical bone strength at the organ and tissue levels, lower BMD values at the spine, tibia and whole body, alterations of microarchitectural properties of trabecular and cortical bone as well as alterations of tissue material properties materialized by modifications of mineral and collagen compartments. Despite the relatively short time involved, treatment of $d b / d b$ mice with [D-Ala2]GIP-Oxm for 21 days improved bone strength at the organ and tissue levels, improved trabecular but not cortical microarchitectural properties and improved tissue material properties.

As expected, 12 week old $d b / d b$ mice displayed increased body weight, enhanced fat mass moderate hyperinsulinemia and severe hyperglycaemia, with substantial glucose intolerance [10,11]. In contrast to a recent study in high-fat fed mice, [D-Ala ${ }^{2}$ GIP-Oxm administration had no significant effect on body weight, non-fasting plasma glucose or glucose tolerance in $d b / d b$ mice [34]. However, values tended to be lower and non-fasting plasma insulin concentrations were significantly increased on day 20 in treated $d b / d b$ mice. This difference in efficacy with high fat fed mice reflects the greater severity of diabetes in the present study, as even after food was withdrawn for $18 \mathrm{~h}$, plasma glucose levels in $d b / d b$ mice were still very high at around $22.5 \mathrm{mmol} / \mathrm{l}$. We do not believe that triple agonism of glucagon as well as GLP-1 and GIP receptors is the reason for lack of effect in these mice with betacell degeneration, because we have recently shown that a different stable Oxm analogue, (D$\left.\mathrm{Ser}^{2}\right) \mathrm{Oxm}\left[\mathrm{Lys}{ }^{38} \mathrm{PAL}\right]$, can ameliorate type 1 diabetes in streptozotocin treated mice when administered twice daily [51]. Thus, it seems likely that a greater dose is required in $\mathrm{db} / \mathrm{db}$ mice to counter the diabetes. However, absence of substantial changes in glycaemic control allows us to evaluate the direct effects of [D-Ala2]GIP-Oxm on bone which are independent of metabolic change. 
Insulin is known to induce bone formation and previously, we clearly revealed that hypoinsulinemia in STZ-diabetic mice contributes to bone loss [23, 52]. In the present study using leptin receptor-deficient $\mathrm{db} / \mathrm{db}$ mice, we found that total, tibia and lumbar bone mineral density together with bone mineral content were significantly decreased in $d b / d b$ mice despite hyperinsulinemia. These results support earlier observations of reduced BMD and BMC in mice lacking leptin receptors [2]. One of the possible contributing factors to the reductions of bone mass in $d b / d b$ mice is loss in leptin signalling. Osteoblasts and adipocytes are derived from the same progenitors, marrow stromal cells (MSCs), and interestingly, leptin receptors are expressed on human MSCs [7]. In addition, the ability of leptin to dose-dependently enhance osteoblastic protein expression and reduce adipocyte biomarkers in cultures of MSCs, emphasises the importance of leptin in controlling differentiation pathways of MSC precursors towards osteoblasts or adipocytes [7]. As a result of defective leptin signal transduction, differentiation of precursors is shifted to adipogenesis, resulting in increased body weight and bone loss, leading to bone impairments. This was confirmed in the present study by an increase in marrow adiposity in $\mathrm{db} / \mathrm{db}$ mice irrespective of treatments. In our study, a higher number of osteoclasts was found either at the surface of trabecula and on the endosteal and periosteal envelopes. This is in agreement with the work of Holloway and co-workers who reported that leptin inhibited osteoclast differentiation [53]. As such, deficiency in leptin signalling may enhance generation of osteoclasts and increase osteoclastic bone resorptive activity, resulting in further bone loss, as evidenced in the present study. However, the non-significant increase in BFR/BS in trabecular bone and Ct.MAR in cortical bone seem to argue against an anabolic action of leptin and might be secondary to higher bone resorption or due to obesity and diabetes itself. [D-Ala ${ }^{2}$ GIP-Oxm did not have a remarkable effect on BMD and BMC at any sites of $d b / d b$ mouse when compared to saline-treated $d b / d b$ controls. This is not necessarily surprising given the relatively short observation period, and it is plausible that extended treatment with [D-Ala ${ }^{2}$ GIP-Oxm would have resulted in changes picked up by DEXA measurements.

Previous studies in leptin signalling deficient diabetic animals, including ZDF rats, fa/fa rats and $d b / d b$ mice, have reported lower bone strength at the organ level $[5,54-56]$. In the present study, we evidenced a reduction in bone strength at the organ level with significant lower values for ultimate load, ultimate displacement, stiffness and work-to-failure. In diabetic $d b / d b$ mice, load deformation curves evidenced a bone that is more brittle with little plastic deformation as compared to salineinjected control animals. Short-term treatment with [D-Ala²]GIP-Oxm in diabetic animals was capable of preserving plastic deformation in a manner comparable to saline-injected normal control mice as evidenced by similar ultimate displacement values. This triple agonist also improved work-to-failure in diabetic mice, likely by preserving plastic deformation, although ultimate load and stiffness were unchanged as compared to saline-injected diabetic mice.

Further assessment of trabecular and cortical microarchitecture revealed that $d b / d b$ mice had profound alterations of these two properties. Although controversy on the anabolic or catabolic actions 
of leptin signalling have been reported in the past years, our results are in agreement with the recent evidence provided by Williams and et al., who observed similar modifications of trabecular and cortical microarchitecture in $d b / d b$ mice [5]. Cellular assessment at both compartment suggested that diabetic mice present with a higher bone turnover. Microstructural examination demonstrated that [D-Ala²]GIPOxm was capable of improving trabecular microarchitecture but failed to evidence any effects on cortical microarchitecture. At the cellular level, the effect of [D-Ala'2]GIP-Oxm, seemed to be due to a reduction in bone turnover. In the light of bone strength improvement observed in 3-point bending experiments in [D-Ala $\left.{ }^{2}\right]$ GIP-Oxm-treated animals, it is likely that the effect of this triple agonist is on tissue material properties.

Previous investigations reported a lower elastic modulus at the tissue level in $\mathrm{db} / \mathrm{db}$ mice [5]. In the present study, we also evidenced lower indentation modulus, but also reductions in hardness and dissipated energy in saline-treated diabetic mice versus saline-injected normal control mice. Interestingly, treatment with [D-Ala2]GIP-Oxm improved hardness and indentation modulus, illustrating clear effects of this triple agonist on tissue material properties in diabetic mice. It is noteworthy that we previously reported that animals lacking either the GIP, GLP-1 or both incretin receptors presented with alterations of bone strength at the tissue level, supporting an important action of these gut hormones [21-23]. In order to ascertain what modifications of tissue material properties were ongoing in $d b / d b$ mice, we examined the overall tissue mineral density distribution by qBEI. Unexpectedly we observed that saline-treated diabetic mice presented with higher mean calcium content and higher calcium heterogeneity as compared with controls. Regarding the apparent increase in bone turn-over at the cellular level, it seemed puzzling that the mean calcium content was increased. However, mathematical computed modelling of bone mineral density distribution revealed that the observed Gaussian pattern is possible only if two independent processes change, namely (i) the frequency of bone remodelling, that leads to a certain bone turn-over rate and (ii) the time course of matrix mineralization $[57,58]$. Exact knowledge of the underlying mineralization process is still lacking, but it should be noted that once mineralization has started in the newly-formed bone matrix, the mineral content is rapidly increasing within few days up to $70 \%$ of its final value and then reaches a plateau with a much slower increase in mineral content [59,60]. The calcium content at which matrix mineralization turns from rapid to slow is accessible by $\mathrm{qBEl}$ and is referred to as $\mathrm{Ca}_{\text {turn }}$ [50]. Investigations of $\mathrm{Ca}_{\text {turn }}$ in newly-formed bone evidenced that in saline-treated diabetic $\mathrm{db} / \mathrm{db}$ mice, this parameter was significantly increased as compared with normal mice, suggesting that matrix mineralization had changed. Similarly, [D-Ala²]GIP-Oxm-treated diabetic animals presented with higher mean calcium content and heterogeneity in the matrix. However, in regard to the lower boneturnover and lower $\mathrm{Ca}_{\text {turn }}$ values, this suggests that [D-Ala2]GIP-Oxm should result in higher mean calcium content and lower heterogeneity. Nevertheless, as the treatment period was short, and given that most of the bone matrix had been formed and mineralized before administration of [D-Ala²]GIPOxm, it is likely that the increase in mean calcium content and calcium heterogeneity reflects modifications of matrix mineralization observed in saline-injected diabetic mice. Longer term studies would be required to fully assess the effects of [D-Ala²]GIP-Oxm on matrix mineralization. 
In view of the relatively short-duration of treatment, we then assessed tissue material properties at bone formation site. Diabetic mice did not exhibit any modification of the mineral compartment as compared to saline-injected controls or [D-Ala²]GIP-Oxm treated mice. The lack of significant modifications in the mineral-to-matrix ratio seems in contradiction with the observed variations in $\mathrm{Ca}_{\text {turn }}$. However, it is noteworthy that saline-treated and [D-Ala²]GIP-Oxm-treated diabetic mice exhibit trends to the same changes in matrix-to-mineral ratios as observed for $\mathrm{Ca}_{\text {turn }}$. The differences between these two parameters, that somehow investigate the same mineralization process, might reside with the spatial resolution of qBEI and FTIRM. In qBEI, with our experimental settings, spatial resolution was $0.5 \mu \mathrm{m}$. However, in FTIRM, mineral signal is best around $900-1200 \mathrm{~cm}^{-1}$ and hence at these wavenumbers, the spatial resolution is around $\sim 10 \mu \mathrm{m}$. Investigations of the collagen compartment revealed that saline-treated diabetic mice presented with increased collagen glycation and reduced collagen maturity as compared to saline-injected controls and that these modifications were reversed by [D-Ala $\left.{ }^{2}\right]$ GIP-Oxm. These findings are in agreement with previous studies investigating collagen properties in connection with GIP and GLP-1 signalling [21-23, 27, 61]. It is likely that these modifications of the collagen compartment participated to the improved bone strength at the tissue but also organ level. In the present study, collagen glycation has been reported as the ratio between the sub-band located at $1032 \mathrm{~cm}^{-1}$ over Amide I. This ratio has been demonstrated specific of collagen glycation as compared with the less validated $900-1200 \mathrm{~cm}^{-1} /$ Amide I that takes into account subbands representative of protein phosphorylation and glycosaminoglycans [45]. However, the 1338/Amide II ratio was unchanged between the three groups of animals. Although the significance of this ratio remains to be elucidated, it has been previously demonstrated that the $1338 \mathrm{~cm}^{-1}$ peak is greatly affected by collagenase treatment and seems to be related to collagen helical integrity in bone and other connective tissues [45, 62, 63]. Furthermore, collagen orientations was altered in salinetreated $\mathrm{db} / \mathrm{db}$ mice and restored in GIP-Oxm-treated $\mathrm{db} / \mathrm{db}$ mice as compared with controls and these results are in agreement with previous observations reported by others [64, 65]. On the other hand, further work will be required to ascertain whether crack propagation and toughness are also improved in response to [D-Ala²]GIP-Oxm.

In conclusion, this study reveals that bone strength both at the organ and tissue levels is detrimentally altered in $d b / d b$ mice and accompanied by profound modifications of microarchitectural and material properties. Moreover, the DPP-4 resistant [D-Ala ${ }^{2}$ GIP-Oxm analogue elicits significant beneficial effects on trabecular microarchitecture and cortical tissue material properties that resulted in improvement in bone strength at the tissue and organ level. The positive effects of triple-activation of GIP, GLP-1 and glucagon receptors by [D-Ala ${ }^{2}$ GIP-Oxm on bone quality in $d b / d b$ mice, independent of significant changes in glycaemic status, provides additional evidence for including incretins as possible new therapeutic strategies for bone-related diseases. 


\section{ACKNOWLEDGEMENTS}

The authors are grateful to Nadine Gaborit and Stéphanie Lemière (LUNAM Université, GEROMLHEA, Institut de Biologie en Santé, Angers, France) for their help with microCT.

\section{FUNDING}

This work was supported by grants from the University of Angers and the University of Ulster Research Challenge Fund and Proof of Principle Funding Programs.

\section{DUALITY OF INTEREST}

No conflict of interest to declare

\section{CONTRIBUTION STATEMENT}

Sity Aishah Mansur: acquisition of data and analysis, interpretation of data, revising the manuscript Aleksandra Mieczkowska: acquisition of data and analysis, interpretation of data, revising the manuscript

Peter R Flatt: Conception and Design, interpretation of data, drafting and revising the manuscript Beatrice Bouvard: Interpretation of data, revising the manuscript

Daniel Chappard: Interpretation of data, revising the manuscript Nigel Irwin: Conception and Design, interpretation of data, drafting and revising the manuscript Guillaume Mabilleau: Conception and Design, acquisition of data and analysis, interpretation of data, drafting and revising the manuscript

All authors approved the current version of the manuscript. 


\section{REFERENCES}

[1] Federation ID. IDF Diabetes Atlas. 6th Edition ed; 2013.

[2] Ealey KN, Fonseca D, Archer MC, Ward WE. Bone abnormalities in adolescent leptin-deficient mice. Regul Pept 2006;136: 9-13.

[3] Ionova-Martin SS, Do SH, Barth HD, Szadkowska M, Porter AE, Ager JW, 3rd, Ager JW, Jr., Alliston T, Vaisse C, Ritchie RO. Reduced size-independent mechanical properties of cortical bone in high-fat diet-induced obesity. Bone 2010;46: 217-25.

[4] Patsch JM, Kiefer FW, Varga P, Pail P, Rauner M, Stupphann D, Resch H, Moser D, Zysset PK, Stulnig TM, Pietschmann P. Increased bone resorption and impaired bone microarchitecture in short-term and extended high-fat diet-induced obesity. Metabolism 2011;60: 243-9.

[5] Williams GA, Callon KE, Watson M, Costa JL, Ding Y, Dickinson M, Wang Y, Naot D, Reid IR, Cornish J. Skeletal phenotype of the leptin receptor-deficient db/db mouse. J Bone Miner Res 2011;26: 1698-709.

[6] Friedman JM, Halaas JL. Leptin and the regulation of body weight in mammals. Nature 1998;395: 763-70.

[7] Thomas T, Gori F, Khosla S, Jensen MD, Burguera B, Riggs BL. Leptin acts on human marrow stromal cells to enhance differentiation to osteoblasts and to inhibit differentiation to adipocytes. Endocrinology 1999;140: 1630-8.

[8] Chen H, Charlat O, Tartaglia LA, Woolf EA, Weng X, Ellis SJ, Lakey ND, Culpepper J, Moore KJ, Breitbart RE, Duyk GM, Tepper RI, Morgenstern JP. Evidence that the diabetes gene encodes the leptin receptor: identification of a mutation in the leptin receptor gene in $\mathrm{db} / \mathrm{db}$ mice. Cell 1996;84: 491-5.

[9] Tartaglia LA, Dembski M, Weng X, Deng N, Culpepper J, Devos R, Richards GJ, Campfield LA, Clark FT, Deeds J, Muir C, Sanker S, Moriarty A, Moore KJ, Smutko JS, Mays GG, Wool EA, Monroe CA, Tepper RI. Identification and expression cloning of a leptin receptor, OB-R. Cell 1995;83: 1263-71.

[10] Coleman DL. Obese and diabetes: two mutant genes causing diabetes-obesity syndromes in mice. Diabetologia 1978;14: 141-8.

[11] Flatt PR, Bailey CJ, Kwasowski P, Swanston-Flatt SK, Marks V. Abnormalities of GIP in spontaneous syndromes of obesity and diabetes in mice. Diabetes 1983;32: 433-5.

[12] Wang B, Chandrasekera PC, Pippin JJ. Leptin- and leptin receptor-deficient rodent models: relevance for human type 2 diabetes. Curr Diabetes Rev 2014;10: 131-45.

[13] Burguera B, Hofbauer LC, Thomas T, Gori F, Evans GL, Khosla S, Riggs BL, Turner RT. Leptin reduces ovariectomy-induced bone loss in rats. Endocrinology 2001;142: 3546-53.

[14] Ducy P, Amling M, Takeda S, Priemel M, Schilling AF, Beil FT, Shen J, Vinson C, Rueger JM, Karsenty G. Leptin inhibits bone formation through a hypothalamic relay: a central control of bone mass. Cell 2000;100: 197-207.

[15] Hamrick MW, Pennington C, Newton D, Xie D, Isales C. Leptin deficiency produces contrasting phenotypes in bones of the limb and spine. Bone 2004;34: 376-83. 
[16] Iwaniec UT, Boghossian S, Lapke PD, Turner RT, Kalra SP. Central leptin gene therapy corrects skeletal abnormalities in leptin-deficient ob/ob mice. Peptides 2007;28: 1012-9.

[17] Turner RT, Kalra SP, Wong CP, Philbrick KA, Lindenmaier LB, Boghossian S, Iwaniec UT. Peripheral leptin regulates bone formation. J Bone Miner Res 2013;28: 22-34.

[18] Baggio LL, Drucker DJ. Biology of incretins: GLP-1 and GIP. Gastroenterology 2007;132: 2131-57.

[19] Drucker DJ. Enhancing incretin action for the treatment of type 2 diabetes. Diabetes Care 2003;26: 2929-40.

[20] Gaudin-Audrain C, Irwin N, Mansur S, Flatt PR, Thorens B, Basle M, Chappard D, Mabilleau G. Glucose-dependent insulinotropic polypeptide receptor deficiency leads to modifications of trabecular bone volume and quality in mice. Bone 2013;53: 221-30.

[21] Mabilleau G, Mieczkowska A, Irwin N, Flatt PR, Chappard D. Optimal bone mechanical and material properties require a functional glucagon-like peptide-1 receptor. J Endocrinol 2013;219: 59-68.

[22] Mieczkowska A, Irwin N, Flatt PR, Chappard D, Mabilleau G. Glucose-dependent insulinotropic polypeptide (GIP) receptor deletion leads to reduced bone strength and quality. Bone 2013;56: 337-42.

[23] Mansur SA, Mieczkowska A, Bouvard B, Flatt PR, Chappard D, Irwin N, Mabilleau G. Stable Incretin Mimetics Counter Rapid Deterioration of Bone Quality in Type 1 Diabetes Mellitus. J Cell Physiol 2015;230: 3009-18.

[24] Tsukiyama K, Yamada Y, Yamada C, Harada N, Kawasaki Y, Ogura M, Bessho K, Li M, Amizuka N, Sato M, Udagawa N, Takahashi N, Tanaka K, Oiso Y, Seino Y. Gastric inhibitory polypeptide as an endogenous factor promoting new bone formation after food ingestion. Mol Endocrinol 2006;20: 1644-51.

[25] Xie D, Cheng H, Hamrick M, Zhong Q, Ding KH, Correa D, Williams S, Mulloy A, Bollag W, Bollag RJ, Runner RR, McPherson JC, Insogna K, Isales CM. Glucose-dependent insulinotropic polypeptide receptor knockout mice have altered bone turnover. Bone 2005;37: 759-69.

[26] Yamada C, Yamada Y, Tsukiyama K, Yamada K, Udagawa N, Takahashi N, Tanaka K, Drucker DJ, Seino Y, Inagaki N. The murine glucagon-like peptide-1 receptor is essential for control of bone resorption. Endocrinology 2008;149: 574-9.

[27] Mabilleau G, Mieczkowska A, Irwin N, Simon Y, Audran M, Flatt PR, Chappard D. Beneficial effects of a N-terminally modified GIP agonist on tissue-level bone material properties. Bone 2014;63: 61-8.

[28] Torekov SS, Harslof T, Rejnmark L, Eiken P, Jensen JB, Herman AP, Hansen T, Pedersen O, Holst JJ, Langdahl BL. A functional amino acid substitution in the glucose-dependent insulinotropic polypeptide receptor (GIPR) gene is associated with lower bone mineral density and increased fracture risk. J Clin Endocrinol Metab 2014;99: E729-33.

[29] Irwin N, Flatt PR. Enteroendocrine hormone mimetics for the treatment of obesity and diabetes. Curr Opin Pharmacol 2013;13: 989-95. 
[30] Baggio LL, Huang Q, Brown TJ, Drucker DJ. Oxyntomodulin and glucagon-like peptide-1 differentially regulate murine food intake and energy expenditure. Gastroenterology 2004;127: 546-58.

[31] Schjoldager BT, Baldissera FG, Mortensen PE, Holst JJ, Christiansen J. Oxyntomodulin: a potential hormone from the distal gut. Pharmacokinetics and effects on gastric acid and insulin secretion in man. Eur J Clin Invest 1988;18: 499-503.

[32] Cohen MA, Ellis SM, Le Roux CW, Batterham RL, Park A, Patterson M, Frost GS, Ghatei MA, Bloom SR. Oxyntomodulin suppresses appetite and reduces food intake in humans. J Clin Endocrinol Metab 2003;88: 4696-701.

[33] Hinke SA, Gelling RW, Pederson RA, Manhart S, Nian C, Demuth HU, Mclntosh CH. Dipeptidyl peptidase IV-resistant [D-Ala(2)]glucose-dependent insulinotropic polypeptide (GIP) improves glucose tolerance in normal and obese diabetic rats. Diabetes 2002;51: 652-61.

[34] Bhat VK, Kerr BD, Flatt PR, Gault VA. A novel GIP-oxyntomodulin hybrid peptide acting through GIP, glucagon and GLP-1 receptors exhibits weight reducing and anti-diabetic properties. Biochem Pharmacol 2013;85: 1655-62.

[35] Chappard D, Baslé MF, Legrand E, Audran M. New laboratory tools in the assessment of bone quality. Osteoporos Int 2011;22: 2225-2240.

[36] Coleman DL, Hummel KP. Studies with the mutation, diabetes, in the mouse. Diabetologia 1967;3: 238-48.

[37] Flatt PR, Bailey CJ. Abnormal plasma glucose and insulin responses in heterozygous lean (ob/+) mice. Diabetologia 1981;20: 573-7.

[38] Bouxsein ML, Boyd SK, Christiansen BA, Guldberg RE, Jepsen KJ, Muller R. Guidelines for assessment of bone microstructure in rodents using micro-computed tomography. J Bone Miner Res 2010;25: 1468-86.

[39] Chappard D. Technical aspects: How do we best prepare bone samples for proper histological analysis? In: Heymann D, editor. Bone cancer: progression and therapeutic approaches. $2^{\text {nd }}$ edition ed. London: Acad. Press; Elsevier Inc.; 2014, p. 111-120.

[40] Chappard D, Alexandre C, Riffat G. Histochemical identification of osteoclasts. Review of current methods and reappraisal of a simple procedure for routine diagnosis on undecalcified human iliac bone biopsies. Basic Appl Histochem 1983;27: 75-85.

[41] Dempster DW, Compston JE, Drezner MK, Glorieux FH, Kanis JA, Malluche H, Meunier PJ, Ott SM, Recker RR, Parfitt AM. Standardized nomenclature, symbols, and units for bone histomorphometry: a 2012 update of the report of the ASBMR Histomorphometry Nomenclature Committee. J Bone Miner Res 2013;28: 2-17.

[42] Ascenzi MG, Lomovtsev A. Collagen orientation patterns in human secondary osteons, quantified in the radial direction by confocal microscopy. J Struct Biol 2006;153: 14-30.

[43] Mieczkowska A, Mansur S, Bouvard B, Flatt PR, Thorens B, Irwin N, Chappard D, Mabilleau G. Double incretin receptor knock-out (DIRKO) mice present with alterations of trabecular and cortical micromorphology and bone strength. Osteoporos Int 2015;26: 209-18. 
[44] Turner CH, Burr DB. Basic biomechanical measurements of bone: a tutorial. Bone 1993;14: 595-608.

[45] Mieczkowska A, Mansur SA, Irwin N, Flatt PR, Chappard D, Mabilleau G. Alteration of the bone tissue material properties in type 1 diabetes mellitus: A Fourier transform infrared microspectroscopy study. Bone 2015;76: 31-9.

[46] Boskey AL, DiCarlo E, Paschalis E, West P, Mendelsohn R. Comparison of mineral quality and quantity in iliac crest biopsies from high- and low-turnover osteoporosis: an FT-IR microspectroscopic investigation. Osteoporos Int 2005;16: 2031-8.

[47] Paschalis EP, DiCarlo E, Betts F, Sherman P, Mendelsohn R, Boskey AL. FTIR microspectroscopic analysis of human osteonal bone. Calcif Tissue Int 1996;59: 480-7.

[48] Paschalis EP, Verdelis K, Doty SB, Boskey AL, Mendelsohn R, Yamauchi M. Spectroscopic characterization of collagen cross-links in bone. J Bone Miner Res 2001;16: 1821-8.

[49] Oliver WC, Pharr GM. An improved technique for determining hardness and elastic modulus using load and displacement sensing indentation experiments. J Mater Res 1992;7: 15641583.

[50] Roschger P, Paschalis EP, Fratzl P, Klaushofer K. Bone mineralization density distribution in health and disease. Bone 2008;42: 456-66.

[51] Irwin N, Pathak V, Pathak NM, Gault VA, Flatt PR. Sustained treatment with a stable longacting oxyntomodulin analogue improves metabolic control and islet morphology in an experimental model of type 1 diabetes. Diabetes Obes Metab 2015;17: 887-95.

[52] Cornish J, Callon KE, Reid IR. Insulin increases histomorphometric indices of bone formation In vivo. Calcif Tissue Int 1996;59: 492-5.

[53] Holloway WR, Collier FM, Aitken CJ, Myers DE, Hodge JM, Malakellis M, Gough TJ, Collier GR, Nicholson GC. Leptin inhibits osteoclast generation. J Bone Miner Res 2002;17: 200-9.

[54] Cornish J, Callon KE, Bava U, Lin C, Naot D, Hill BL, Grey AB, Broom N, Myers DE, Nicholson GC, Reid IR. Leptin directly regulates bone cell function in vitro and reduces bone fragility in vivo. J Endocrinol 2002;175: 405-15.

[55] Prisby RD, Swift JM, Bloomfield SA, Hogan HA, Delp MD. Altered bone mass, geometry and mechanical properties during the development and progression of type 2 diabetes in the Zucker diabetic fatty rat. J Endocrinol 2008;199: 379-88.

[56] Reinwald S, Peterson RG, Allen MR, Burr DB. Skeletal changes associated with the onset of type 2 diabetes in the ZDF and ZDSD rodent models. Am J Physiol Endocrinol Metab 2009;296: E765-74.

[57] Ruffoni D, Fratzl P, Roschger P, Klaushofer K, Weinkamer $R$. The bone mineralization density distribution as a fingerprint of the mineralization process. Bone 2007;40: 1308-19.

[58] Ruffoni D, Fratzl P, Roschger P, Phipps R, Klaushofer K, Weinkamer R. Effect of temporal changes in bone turnover on the bone mineralization density distribution: a computer simulation study. J Bone Miner Res 2008;23: 1905-14.

[59] Boivin G, Meunier PJ. Changes in bone remodeling rate influence the degree of mineralization of bone. Connect Tissue Res 2002;43: 535-7. 
[60] Misof BM, Roschger P, Cosman F, Kurland ES, Tesch W, Messmer P, Dempster DW, Nieves J, Shane E, Fratzl P, Klaushofer K, Bilezikian J, Lindsay R. Effects of intermittent parathyroid hormone administration on bone mineralization density in iliac crest biopsies from patients with osteoporosis: a paired study before and after treatment. J Clin Endocrinol Metab 2003;88: 1150-6.

[61] Mieczkowska A, Bouvard B, Chappard D, Mabilleau G. Glucose-dependent insulinotropic polypeptide (GIP) directly affects collagen fibril diameter and collagen cross-linking in osteoblast cultures. Bone 2015;74: 29-36.

[62] Boskey A, Pleshko Camacho N. FT-IR imaging of native and tissue-engineered bone and cartilage. Biomaterials 2007;28: 2465-78.

[63] West PA, Torzilli PA, Chen C, Lin P, Camacho NP. Fourier transform infrared imaging spectroscopy analysis of collagenase-induced cartilage degradation. J Biomed Opt 2005;10: 14015.

[64] Ascenzi MG, Lutz A, Du X, Klimecky L, Kawas N, Hourany T, Jahng J, Chin J, Tintut Y, Nackenhors $U$, Keyak J. Hyperlipidemia affects multiscale structure and strength of murine femur. J Biomech 2014;47: 2436-43.

[65] Sage AP, Lu J, Atti E, Tetradis S, Ascenzi MG, Adams DJ, Demer LL, Tintut Y. Hyperlipidemia induces resistance to PTH bone anabolism in mice via oxidized lipids. $\mathrm{J}$ Bone Miner Res 2011;26: 1197-206. 


\section{FIGURE LEGENDS}

Figure 1: Assessment of bone strength at the organ level in saline- and [D-Ala²]GIP-Oxmtreated diabetic mice by three point bending. (A) Examples of load-displacement curves. Saline-injected controls, black line; saline-treated diabetic mice, dashed line; [D-Ala2] GIP-Oxm-treated diabetic mice, grey line. (B) Mechanical parameters recorded at the end of the study. ${ }^{* *}$ and ${ }^{* * *}: p<0.01$ and $p<0.001$ vs. saline-injected controls, respectively. \#\#: $p<0.01$ vs. saline-treated diabetic mice.

Figure 2: Alterations of trabecular microarchitecture in saline- and [D-Ala²]GIP-Oxmtreated diabetic mice. (A) Three dimensional models of trabecular microarchitecture recorded at the proximal tibia metaphysis. (B) Trabecular microarchitecture parameters. ${ }^{*},{ }^{* *}$ and ${ }^{* * *}: p<0.05, p<0.01$ and $p<0.001$ vs. saline-injected controls, respectively. \# and \#\#: $p<0.05$ and $p<0.01$ vs. saline-treated diabetic mice, respectively.

Figure 3: Alterations of cortical microarchitecture in saline- and [D-Ala ${ }^{2}$ GIP-Oxm-treated diabetic mice. (A) Three dimensional models of cortical microarchitecture recorded at the tibia midshaft. (B) Cortical microarchitectural parameters. ${ }^{*},{ }^{* *}$ and ${ }^{* * *}: p<0.05$, $p<0.01$ and $p<0.001$ vs. saline-injected controls, respectively.

Figure 4: Assessment of bone strength at the tissue level in saline- and [D-Ala $\left.{ }^{2}\right]$ GIP-Oxmtreated diabetic mice by nanoindentation. ${ }^{*}$ and ${ }^{* *}: p<0.05$ and $p<0.01$ vs. salineinjected controls, respectively. \#: $p<0.05$ vs. saline-treated diabetic mice.

Figure 5: Bone mineral density distribution (BMDD) in saline- and [D-Ala²]GIP-Oxmtreated diabetic mice. (A) Representative calcium map of saline-injected controls, saline- and [D-Ala2]GIP-Oxm-treated diabetic mice. (B) Characterization of BMDD by $\mathrm{Ca}_{\text {mean }}$ and $\mathrm{Ca}_{\text {width. }}$ (C) Bone mineralization profile and associated $\mathrm{Ca}_{\text {turn }}$ value. (D) Birefringent collagen area showing collagen orientation along the longitudinal axis. * and ${ }^{* *}: p<0.05$ and $p<0.01$ vs. saline-injected controls, respectively. \#\#: $p<0.01$ vs. saline-treated diabetic mice.

Figure 6: Tissue material properties assessed at bone formation site in saline- and [DAla ${ }^{2}$ GIP-Oxm-treated diabetic mice. ${ }^{*}$ and ${ }^{* *}: p<0.05$ and $p<0.01$ vs. saline-injected controls, respectively. \#: $p<0.05$ vs. saline-treated diabetic mice. 
Table 1: Characteristics of [D-Ala²]GIP-Oxm

\begin{tabular}{|c|c|c|c|c|c|}
\hline \multirow{2}{*}{ Peptide } & \multirow{2}{*}{ Sequence } & \multirow{2}{*}{$\begin{array}{l}\text { In vitro DPP-4 } \\
\text { resistance time (h) }\end{array}$} & \multicolumn{3}{|c|}{$\%$ of cAMP production at } \\
\hline & & & GIPr & GLP-1r & GcgR \\
\hline GIP & YAEGTFISDYSIAMDKIHQQDFVNWLLAQKGKKNDWKHNITQ & 2.2 & 100 & - & - \\
\hline Oxyntomodulin & HSQGTFTSDYSKYLDSRRAQDFVQWLMNTKRNRNNIA & 9.3 & - & 100 & 100 \\
\hline [D-Ala²]GIP-Oxm & Y[D-Ala]EGTFISDYSKYLDSRRAQDFVQWLMNTKRNRNNIA & $>24$ & 95 & 77 & 83 \\
\hline
\end{tabular}

Resistance of peptides to degradation by DPP-4 $(5 \mathrm{mU})$ was measured $(\mathrm{n}=3)$ following $0,2,4$ and $8 \mathrm{~h}$ incubations. Reaction products were subsequently analysed by HPLC. For in vitro cAMP production studies, peptides $\left(10^{-6} \mathrm{M}\right)$ were incubated $(20 \mathrm{~min} ; \mathrm{n}=4)$ with GIP-, GLP-1- and glucagon- $\mathrm{R}$ transfected cells [34] and cAMP generation measured by ELISA and presented as a percentage of respective control. Abbreviations: DPP-4, dipeptidyl peptidase 4; GIPr, GIP receptor; GLP-1r, glucagon-like peptide-1 receptor; GcgR, glucagon receptor 
Table 2: Metabolic, compositional and densitometric parameters

\begin{tabular}{|c|c|c|c|}
\hline & $\begin{array}{l}\text { Saline } \\
\text { controls }\end{array}$ & $\begin{array}{c}\text { Saline } \\
\text { diabetic }\end{array}$ & $\begin{array}{c}{\left[\mathrm{D}-\mathrm{Ala}^{2}\right] \text { GIP-Oxm }} \\
\text { diabetic }\end{array}$ \\
\hline Non fasting glucose (mM) & $5.1 \pm 0.5$ & $31.5 \pm 0.8^{* *}$ & $30.4 \pm 0.8^{* *}$ \\
\hline Non fasting insulin (ng/ml) & $1.1 \pm 0.2$ & $0.03 \pm 0.01^{\star *}$ & $0.09 \pm 0.03^{* *, \Delta \Delta}$ \\
\hline Plasma glucose AUC (mM.min) & $205 \pm 14.2$ & $699.6 \pm 133.3$ & $552.5 \pm 50.7$ \\
\hline Plasma insulin AUC (ng/ml.min) & $38.2 \pm 9.8$ & $2.1 \pm 0.6$ & $3.2 \pm 0.9$ \\
\hline Body weight $(\mathrm{g})$ & $25.7 \pm 0.7$ & $39.6 \pm 2.8^{* *}$ & $38.7 \pm 1.5^{* *}$ \\
\hline Fat mass (\%) & $13.2 \pm 0.8$ & $45.2 \pm 2.7^{* *}$ & $44.8 \pm 1.8^{* *}$ \\
\hline Whole body BMD $\left(\mathrm{g} / \mathrm{cm}^{2}\right)$ & $0.052 \pm 0.001$ & $0.039 \pm 0.000^{* *}$ & $0.040 \pm 0.001^{* *}$ \\
\hline Whole body BMC (g) & $0.493 \pm 0.010$ & $0.201 \pm 0.045^{* *}$ & $0.247 \pm 0.013^{* *}$ \\
\hline Lumbar BMD (g/cm²) & $0.064 \pm 0.003$ & $0.043 \pm 0.002^{* *}$ & $0.039 \pm 0.001^{* *}$ \\
\hline Lumbar BMC (g) & $0.040 \pm 0.001$ & $0.019 \pm 0.002^{* *}$ & $0.015 \pm 0.001^{* *}$ \\
\hline Tibia BMD $\left(\mathrm{g} / \mathrm{cm}^{2}\right)$ & $0.059 \pm 0.001$ & $0.044 \pm 0.001^{* *}$ & $0.047 \pm 0.002^{* *}$ \\
\hline Tibia BMC (g) & $0.020 \pm 0.001$ & $0.010 \pm 0.000$ ** & $0.011 \pm 0.000^{* *}$ \\
\hline
\end{tabular}

Parameters were measured after 28 days treatment with saline vehicle or [D-Ala²]GIP-Oxm (50 nmol/kg) in lean control or $d b / d b$ diabetic mice. For glucose tolerance, glucose (18 mmol/kg body weight) was administered in non-fasted mice and 0-60 min plasma glucose and insulin area under the curve (AUC) values calculated. All BMD and BMC measurements were determined using a Lunar PIXImus DEXA scanner on day 28 . Values are mean \pm SEM for ten mice. ${ }^{* *} p<0.01$ vs. saline-treated control mice. ${ }^{\Delta \Delta} p<0.01$ vs. saline-treated $d b / d b$ diabetic mice. Abbreviations: BMD, Bone mineral density; BMC, Bone mineral content; ND, not determined 
(A)

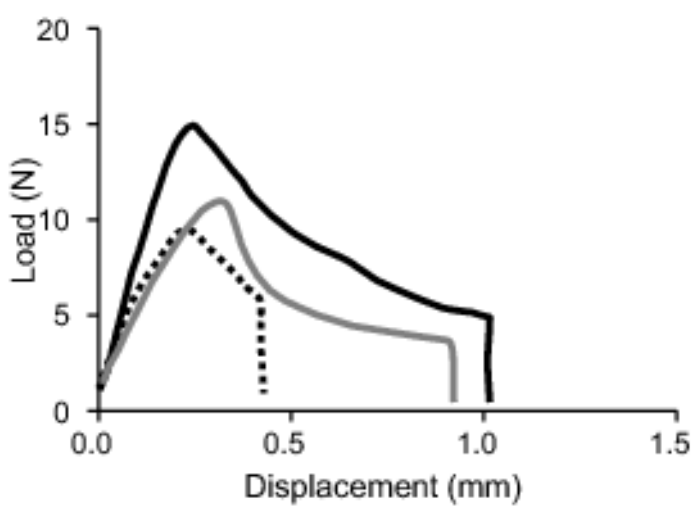

(B)
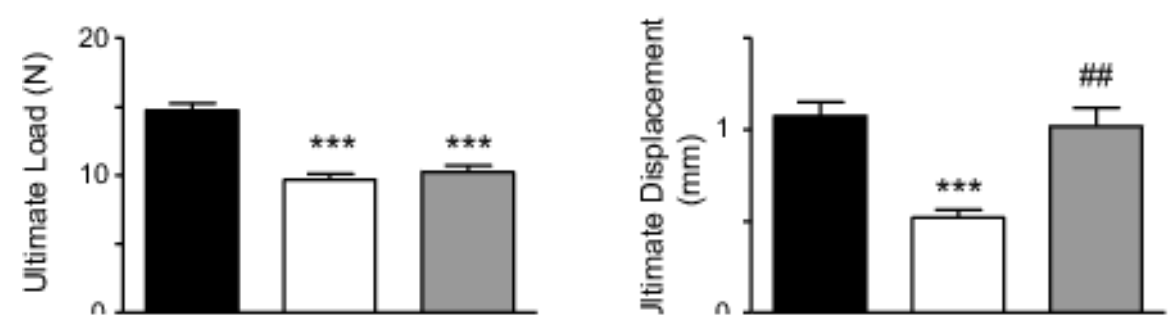

Fig. 1 
(A)

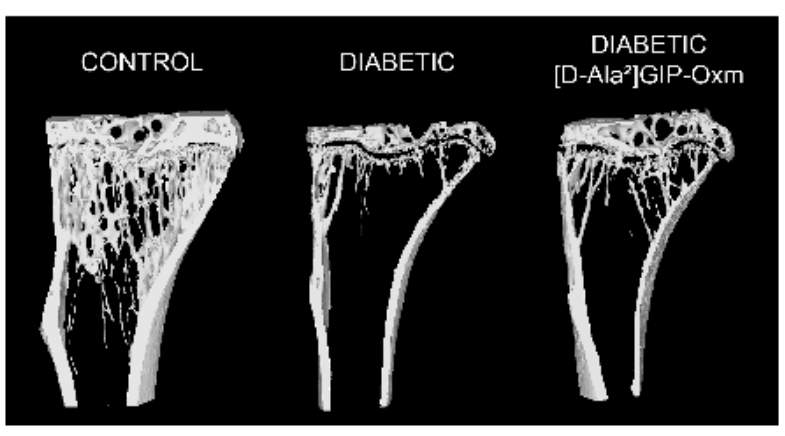

(B)
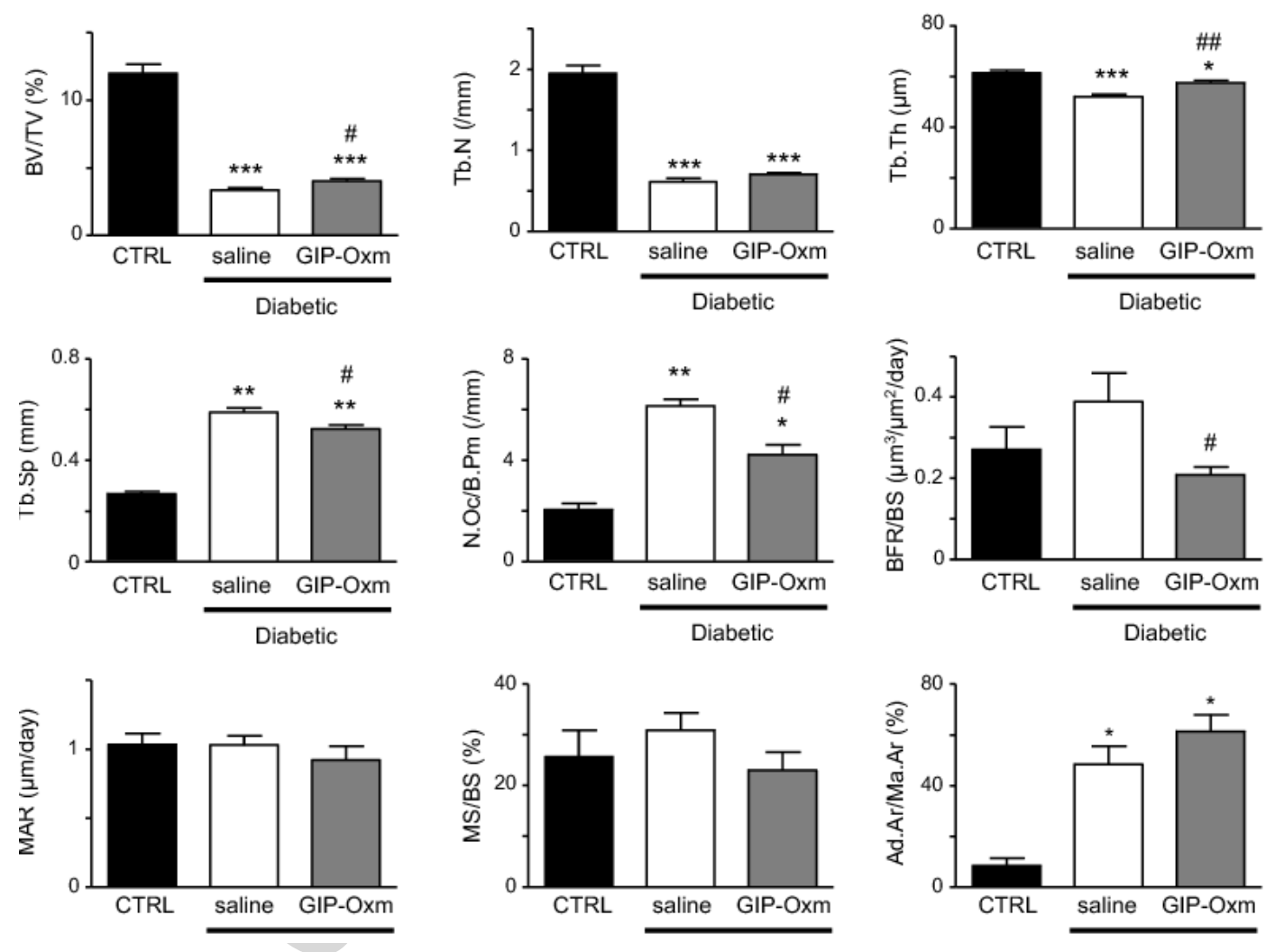

Fig. 2 
(A)

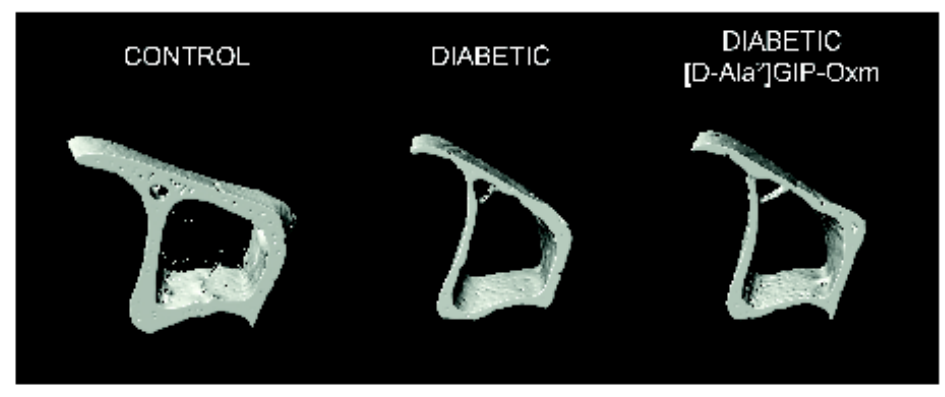

(B)
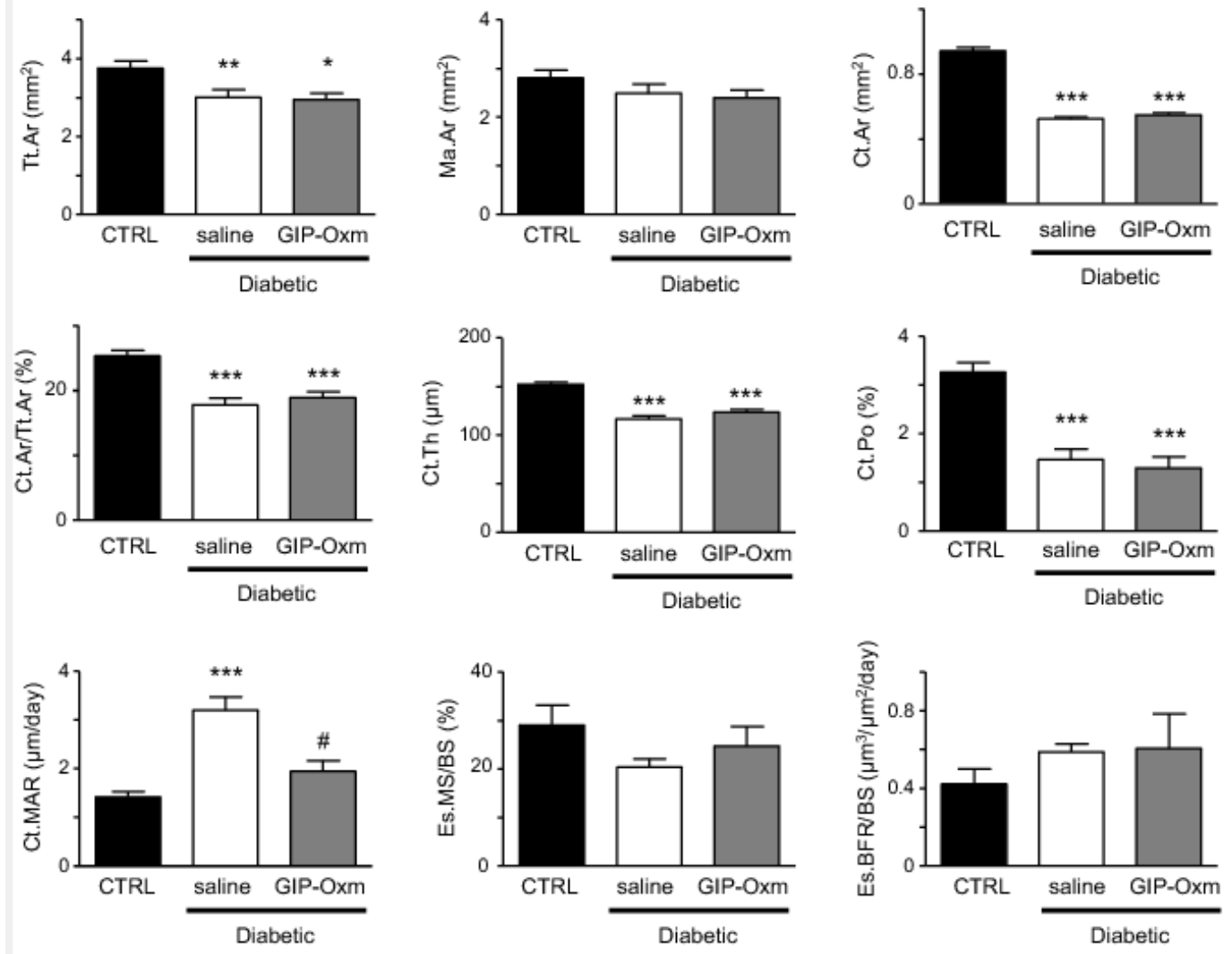

Fig. 3 

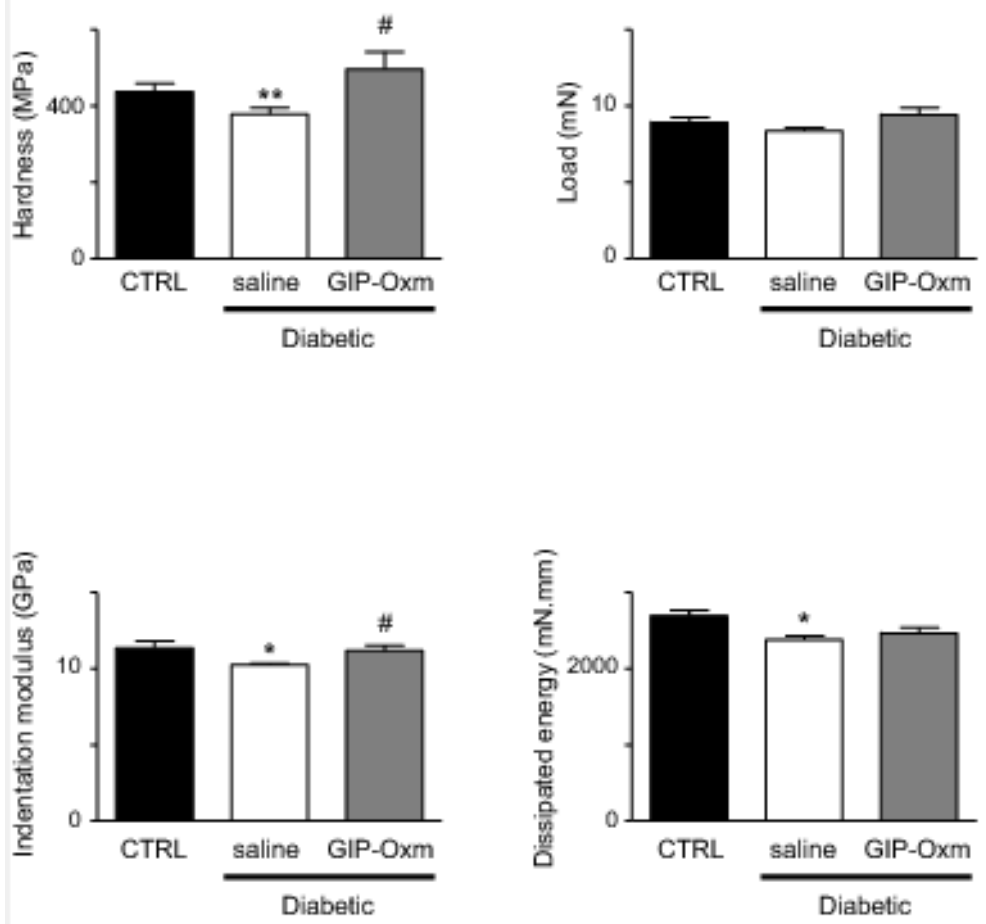

Fig. 4 
(A)

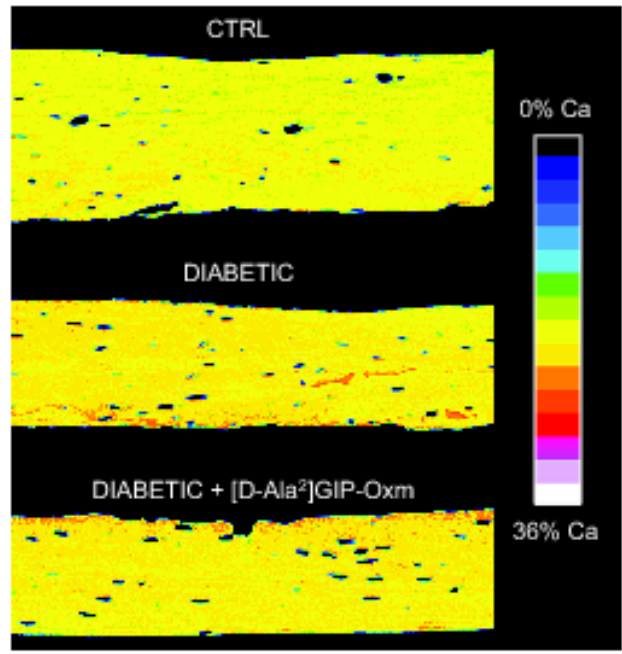

(C)
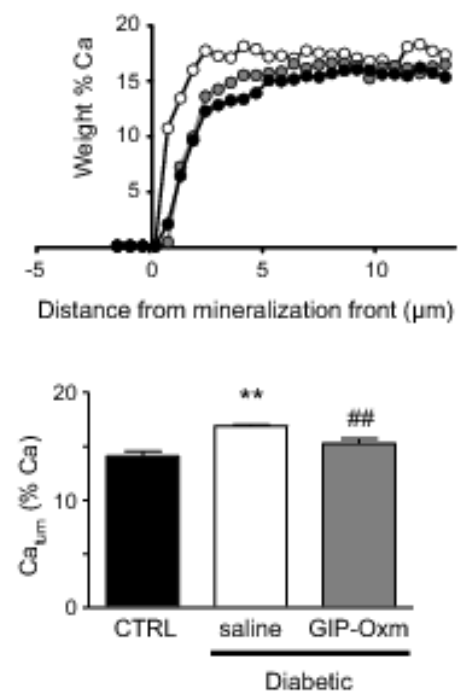
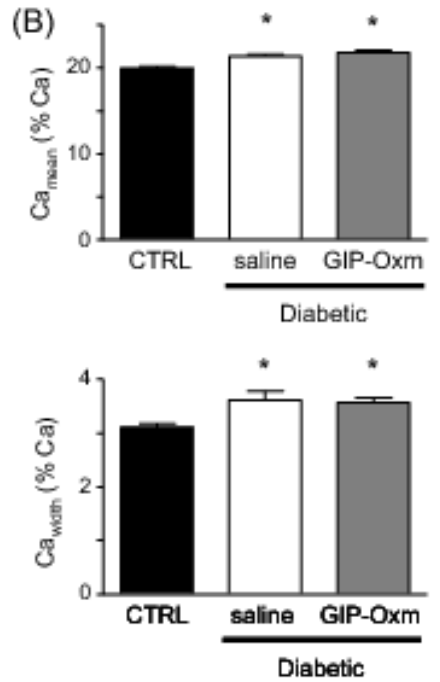

(D)

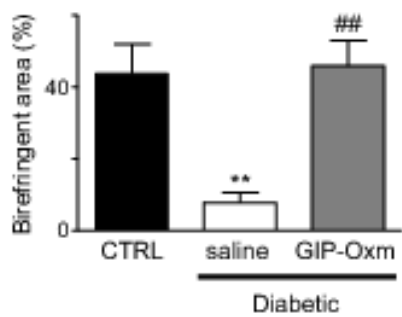

Fig. 5 

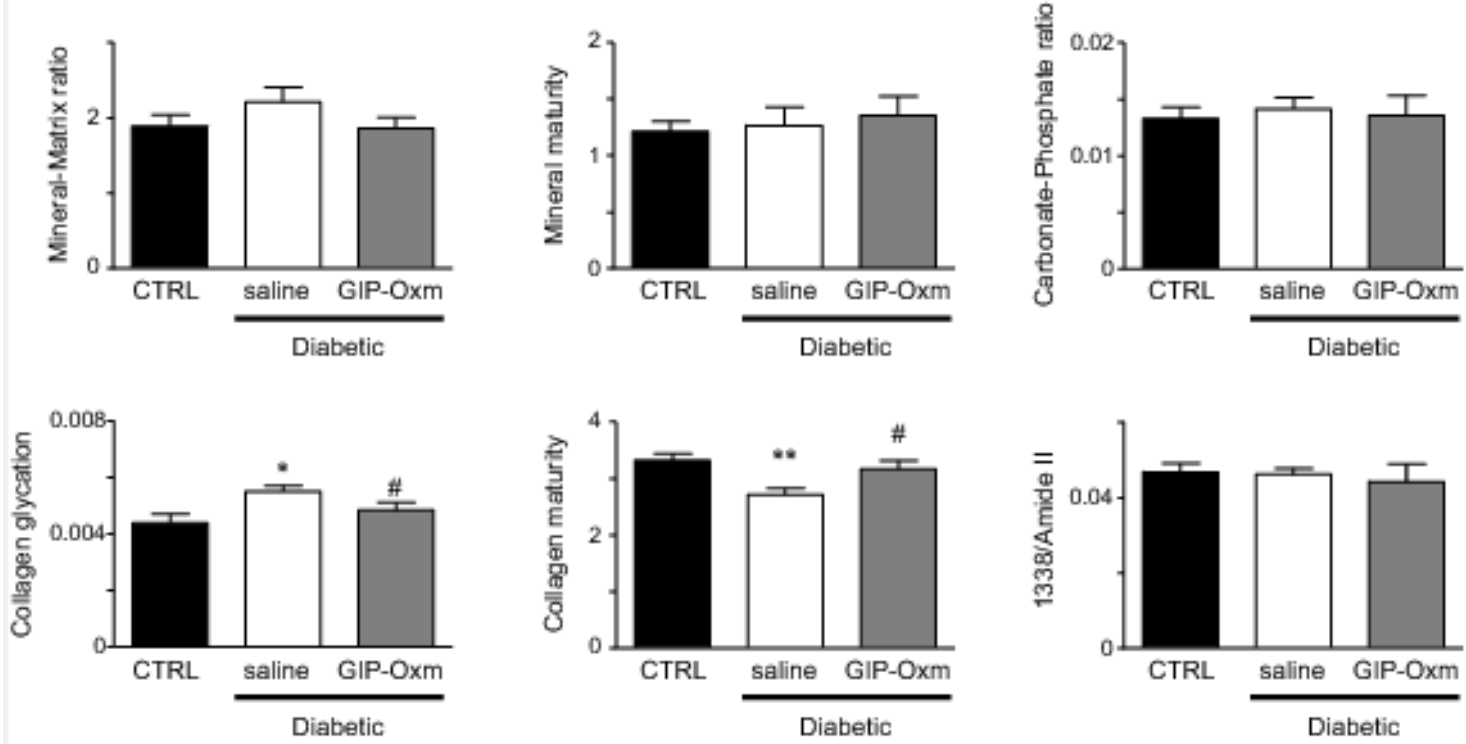

Fig. 6 


\section{HIGHLIGHTS}

- Leptin receptor-deficient mouse presented with dramatic alterations of bone strength at both the organ and tissue level

- Leptin receptor-deficient mouse exhibited deteriorations of trabecular and cortical microarchitectures

- Treatment with [D-Ala²]GIP-Oxm preserved trabecular bone mass and thickness

- Treatment with [D-Ala²]GIP-Oxm improved collagen glycation and maturity 